University of Veterinary Medicine Hannover, ${ }^{1}$ Institute for Animal Breeding and Genetics, ${ }^{2}$ LuFG Ruthe,

${ }^{3}$ Clinic for Poultry, ${ }^{4}$ Institute for Animal Nutrition

BRITTA SCHOLZ ${ }^{1}$, SWAANTJE RÖNCHEN ${ }^{1}$, HENNING HAMANN ${ }^{1}$, CHRISTIAN

SÜRIE $^{2}$, ULRICH NEUMANN ${ }^{3}$, JOSEF KAMPHUES ${ }^{4}$ and OTTMAR DISTL ${ }^{1}$

\title{
Evaluation of bone strength, keel bone deformity and egg quality of laying hens housed in small group housing systems and furnished cages in comparison to an aviary housing system
}

\begin{abstract}
The objective of the study was to assess bone breaking strength, keel bone status and egg quality parameters of Lohmann Silver (LS) and Lohmann Tradition (LT) layers housed in small group systems (SG) and furnished cages (FC) in comparison to an aviary system. At the end of the 3rd, 6th, 9th and 11th laying month, approximately 40 hens were randomly chosen from each housing system and slaughtered (478 hens in total). Humerus and tibia strengths were analysed using a three-point-bending machine. Keel bone status was evaluated on a scale from 1 (severe) to 4 (no deformity). Shell breaking strength was measured every four weeks, totalling 4,887 eggs. Statistical analyses were performed using the MIXED procedure of SAS. Humerus and tibia strengths of LS layers housed in SG were significantly higher compared to LS hens kept in FC. Bone breaking strengths of humerus and tibia in LS and LT layers were highest in the aviary system and the differences to the other housing systems were significant. No significant differences in tibia and humerus bone breaking strengths were found between SG and FC for LT hens. Keel bone status was not significantly influenced by housing system or laying strain. For both hybrids, shell breaking strength was significantly lower in SG compared to FC and aviary system. The results showed that SG systems can significantly enhance bone breaking strength for LS layers in comparison to hens kept in FC. The lower shell breaking strength of eggs in SG might slightly impair economic aspects.
\end{abstract}

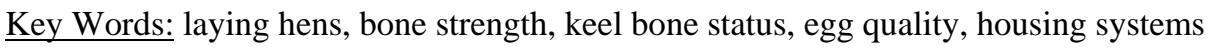

\section{Zusammenfassung}

Titel der Arbeit: Evaluierung des Einflusses von Kleingruppenhaltung und ausgestaltetem Käfig im Vergleich zu einer Volierenhaltung auf Knochenfestigkeit, Brustbeinstatus und Eiqualität bei Legehennen Ziel der vorliegenden Studie war es, Humerus- und Tibiabruchfestigkeiten, Brustbeinstatus sowie ausgewählte Parameter zur Eiqualität der Legelinien Lohmann Silver (LS) und Lohmann Brown (LB) aus ausgestaltetem Käfig (FC) und Kleingruppenhaltung (SG) im Vergleich zu einer Volierenhaltung zu untersuchen. Am Ende des 3., 6., 9. und 11. Legemonats wurden jeweils 40 Hennen aus den drei Haltungssystemen entnommen und geschlachtet (insgesamt 478 Tiere). Die Knochenbruchfestigkeiten wurden mittels einer Materialprüfmaschine gemessen. Der Brustbeinstatus wurde anhand einer Skala von 1 (hochgradig verändert) bis 4 (ohne besonderen Befund) beurteilt. Untersuchungen zur Eiqualität wurden während der Legeperiode in einem Abstand von vier Wochen durchgeführt (insgesamt 4.887 Eier). Die statistische Auswertung erfolgte mit der Prozedur MIXED von SAS. Humerus- und Tibiafestigkeiten der LS Hennen aus SG waren signifikant höher im Vergleich zu LS Hennen aus FC. Für beide Legelinien erwiesen sich die in der Volierenhaltung gemessenen Humerus- und Tibiafestigkeiten im Vergleich zu den zwei übrigen Haltungsformen signifikant am höchsten. Für die LT Hennen konnte kein signifikanter Unterschied in der Humerus- und Tibiaknochenfestigkeit zwischen SG und FC ermittelt werden. Der Brustbeinstatus wurde nicht signifikant von Haltungssystem oder Legelinie beeinflusst. Die Eischalenfestigkeit war für beide Legelinien in SG signifikant niedriger verglichen zu FC und Volierenhaltung. Die Ergebnisse zeigten, dass die Kleingruppenhaltung die Knochenfestigkeit von LS Hennen im Vergleich zu Hennen aus ausgestaltetem Käfig signifikant verbessern konnte. Die niedrigere Schalenfestigkeit aus SG könnte sich möglicherweise negativ auf die Wirtschaftlichkeit dieses Haltungssystems auswirken. 


\section{Introduction}

Since animal welfare plays an increasing role for the consumer, political decisions on laying hen husbandry have become a focal point in the European Union. Due to current legal regulations, conventional cages have to be replaced by alternative housing systems or furnished cages by the end of 2011 in all European countries. In Germany, conventional cages will be forbidden after 2008 and furthermore, furnished cages will be abandoned after 2011 also. Research is strongly required to test small group housing systems, which are currently discussed to replace furnished cages by the end of 2011, thus offering an option to alternative housing systems. Small group systems are designed to house larger groups of hens per compartment and to provide an enriched environment with help of perches, nest box, sand bath and devices to shorten claws. They aim to combine improved animal welfare with the positive hygienic aspects, such as reduced risk of zoonoses and infections that are related to house keeping systems which are well protected from outside environmental influences. So far, health and welfare issues of hens housed in small group systems have not been directly compared to layers housed in an aviary system. The objective of the present investigation was to assess bone breaking strength, keel bone deformity and egg quality of Lohmann Silver (LS) and Lohmann Tradition (LT) laying hens housed in a small group housing system (Eurovent 625a-EU) and furnished cages (Aviplus) in direct comparison to an aviary housing system (Aviary "Natura”).

\section{Materials and methods}

All three housing systems examined (provided by Big Dutchman, Vechta, Germany) were established within separate rooms of one experimental building. The furnished cage system Aviplus (FC) consisted of a three-tier block of double-sided cages with solid side and rear partitions. Group sizes comprised 10 layers (bottom tier), 20 layers (second tier) and 30 hens (top tier). The small group housing system Eurovent 625aEU (SG) was built without a centre partition and accommodated group sizes of 40 and 60 laying hens which were evenly distributed over the three levels. In both systems, each compartment was equipped with perches, litter bath, nest box and claw shortening devices. Perches were incorporated in parallel position to the length of each compartment. In SG, the central tube for the automatic distribution of the dust bathing substrate served as additional perching space. The cage surface area provided was 750 $\mathrm{cm}^{2}$ per hen. The EU legislative standards on keeping laying hens (EU directive 1999/74/EG) were fully met (Tab. 1).

Table 1

Brief description of the three different housing systems tested (Kurze Beschreibung der drei verschiedenen in die Untersuchung einbezogenen Haltungsysteme)

\begin{tabular}{lllllll}
\hline & FC & & SG & & Aviary \\
\hline Group size & 10 & 20 & 30 & 40 & 60 & 1215 \\
Floor space $\left(\mathrm{mm}^{2}\right)$ & $1,206 \times 625$ & $2,412 \times 625$ & $3,618 \times 625$ & $2,412 \times 1,250$ & $3,618 \times 1,250$ & $7,050 \times$ \\
& & & & & & 18,386 \\
Height (mm) & 450 & 450 & 450 & 450 & 450 & 2,350 (c.b.) \\
Space/hen $\left(\mathrm{cm}^{2}\right)$ & 756 & 756 & 756 & 750 & 750 & approx. 1,067 \\
\hline
\end{tabular}

FC: furnished cage system Aviplus; SG: small group system Eurovent 625a-EU; c.b.: central area of aviary system. 
The aviary system (model "Natura") was equipped with a three tier central block and provided access to a covered outdoor area. It consisted of two compartments, each containing 1,215 laying hens. Perches were installed in front of the second level and above the top level. Family nest boxes were attached on the walls opposite the central block. They were connected via footboards with the medium level of the system.

The experimental trial investigated started in July 2004 and ended in July 2005. Two floor-reared, brown layer lines (Lohmann Tradition (LT) and Lohmann Silver (LS)) were transferred to the three housing systems at the age of 18 weeks. Each system tested contained approximately 1,500 layers. All laying hens were subjected to identical management conditions.

At the end of the 3rd, 6th, 9th and 11th laying month approximately 40 hens were randomly chosen from each housing system (considering layer strain and group size to equal numbers) and slaughtered (478 hens in total). Humerus and tibia bones were removed from muscles and tendons and stored for one day $\left(+4^{\circ} \mathrm{C}\right)$ until bone strength analysis. Bone breaking strength $(\mathrm{N})$ was measured by using a three-point-bending machine (“Zwick/Z2,5/TNIS”, Zwick-Roell, Ulm, Germany). Bone ends were placed on two supports and a constant, perpendicular force was applied until bone fracture.

The keel bone status of the layers was evaluated visually and per palpation after removal of the skin. It was recorded on a scale from 1 to $4(1=$ severe deformity, $2=$ moderate deformity, 3 = slight deformity, 4 = no deformity).

With begin of the third laying month, every four weeks a sample of approximately 150 and every 12 weeks a sample of approximately 300 eggs (totalling 4,887) was collected. Shell breaking strength $(\mathrm{N})$ was assessed using the test machine "Zwick/Z2,5/TNIS". Eggshell thickness $(\mu \mathrm{m})$ was defined using a micrometer (QCT from TSS, York, UK). Eggshell density $\left(\mathrm{mg} / \mathrm{cm}^{2}\right)$ was calculated by dividing shell weight by surface area. Results were recorded separately for housing system, layer line, group size and compartment (SG).

Statistical analyses were performed using the MIXED procedure of the SAS package, version 9.1.3 (Statistical Analysis System Institute Inc., Cary, NC, USA, 2007). Traits were analysed for the fixed effects of housing system, layer line, group size and laying month. Two-way and three-way interactions were also tested. The interaction between laying month and individual compartment was treated as a randomly distributed effect. The model for keel bone status and bone breaking strength included body weight of the hens as a linear covariate.

Model for bone breaking strength

$\mathrm{Y}_{\mathrm{ijklmno}}=\mu+\mathrm{SYS}_{\mathrm{i}}+\mathrm{LL}_{\mathrm{j}}+\mathrm{GR}(\mathrm{SYS})_{\mathrm{ik}}+\mathrm{MON}_{\mathrm{l}}+\mathrm{SYS} \mathrm{LL}_{\mathrm{ij}}+\mathrm{SYS}^{*} \mathrm{MON}_{\mathrm{il}}+$ $\mathrm{LL} * \mathrm{GR}(\mathrm{SYS})_{\mathrm{ijk}}+\mathrm{b}$ x BW(LL*MON$)_{\mathrm{jlm}}+\mathrm{MON}^{*} \mathrm{COMP}(\mathrm{LL} * \mathrm{GR}(\mathrm{SYS}))_{\mathrm{ijkln}}+\mathrm{e}_{\mathrm{ijklmn}}$

$\begin{array}{ll}\mathrm{Y}_{\mathrm{ijklmno}} & \text { humerus or tibia bone breaking strength } \\ \mu & \text { model constant } \\ \text { SYS }_{\mathrm{i}} & \text { fixed effect of housing system }(\mathrm{i}=1-3) \\ \mathrm{LL}_{\mathrm{j}} & \text { fixed effect of layer line }(\mathrm{j}=1-2) \\ \left.\mathrm{GR}_{(\mathrm{SYS})}\right)_{\mathrm{ik}} & \text { fixed effect of group size within housing system }(\mathrm{k}=1-6) \\ \text { MON }_{\mathrm{l}} & \text { fixed effect of laying months tested }(\mathrm{l}=1-4)\end{array}$


SYS* $\mathrm{LL}_{\mathrm{ij}} \quad$ fixed effect of the interaction between housing system and layer line

$\mathrm{SYS}^{*} \mathrm{MON}_{\mathrm{il}} \quad$ fixed effect of the interaction between housing system and laying month

$L L^{*} G R(S Y S)_{i j k} \quad$ fixed effect of the interaction between layer line and group size within housing system

b linear regression coefficient

BW body weight of hens before slaughter

MON*COMP(LL*GR(SYS) $)_{\text {ijkln }}$ random effect of interaction between laying month and compartment of housing system within layer line, group size and housing system

$\mathrm{e}_{\mathrm{ijklmn}}$ random error

Model for keel bone status

$\mathrm{Y}_{\mathrm{ijklmno}}=\mu+\mathrm{SYS}_{\mathrm{i}}+\mathrm{LL}_{\mathrm{j}}+\mathrm{GR}(\mathrm{SYS})_{\mathrm{ik}}+\mathrm{MON}_{\mathrm{l}}+\mathrm{SYS}^{*} \mathrm{LL}_{\mathrm{ij}}+\mathrm{SYS}^{*} \mathrm{MON}_{\mathrm{il}}+\mathrm{bx}$ $\mathrm{BW}(\mathrm{LL} * \mathrm{MON})_{\mathrm{jlm}}+\mathrm{MON} * \mathrm{COMP}(\mathrm{LL} * \mathrm{GR}(\mathrm{SYS}))_{\mathrm{ijkln}}+\mathrm{e}_{\mathrm{ijklmn}}$

Model for egg quality traits

$\mathrm{Y}_{\mathrm{ijklmn}}=\mu+\mathrm{SYS}_{\mathrm{i}}+\mathrm{LL}_{\mathrm{j}}+\mathrm{GR}(\mathrm{SYS})_{\mathrm{ik}}+\mathrm{MON}_{\mathrm{l}}+\mathrm{SYS}^{*} \mathrm{LL}_{\mathrm{ij}}+\mathrm{SYS}^{*} \mathrm{MON}_{\mathrm{il}}+$ MON*COMP(LL*GR(SYS) $)_{i j k l m}+e_{i j k l m n}$

$Y_{\mathrm{ijklmn}} \quad$ egg quality traits: shell breaking strength, shell thickness, shell density, egg weight

\section{Results}

Table 2 illustrates the least square means (LSM), standard errors (SE) and error probabilities of variance analysis of bone breaking strength and keel bone status of hens housed in the three different housing systems.

Table 2

Least square means (LSM) and their standard errors (SE) for bone breaking strength and keel bone status for the different housing systems and error probabilities (P) between housing systems (Least Square Mittelwerte (LSM) und deren Standardfehler für die Knochenbruchfestigkeiten nach Haltungssystemen und deren Irrtumswahrscheinlichkeiten (P) zwischen den Haltungssystemen)

\begin{tabular}{llllllllll}
\hline Trait & FC (I) & \multicolumn{3}{c}{ SG (II) } & \multicolumn{3}{c}{ Aviary (III) } & P & \\
& LSM & SE & LSM & SE & LSM & SE & I-II & I-III & II-III \\
\hline Humerus (N) & 170.9 & 4.7 & 185.7 & 4.8 & 287.6 & 9.0 & $*$ & $* * *$ & $* * *$ \\
Tibia (N) & 115.8 & 2.0 & 121.9 & 2.0 & 156.5 & 3.4 & $*$ & $* * *$ & $* * *$ \\
Keel bone (1-4) & 3.54 & 0.06 & 3.51 & 0.06 & 3.43 & 0.09 & n.s. & n.s. & n.s. \\
\hline
\end{tabular}

FC: furnished cage system Aviplus; SG: small group system Eurovent 625a-EU; n.s.: not significant, P > 0.05; *: P $\leq$ 0.05; $* * *: \mathrm{P} \leq 0.001$.

Tibia and humerus breaking strengths of layers were highest in the aviary system. The differences to both the furnished and small group housing system were significant. In comparison to FC, bone breaking strengths of hens kept in SG were significantly higher. Keel bone status was scored highest in FC, but statistically significant differences could not be detected between the three different housing systems. Table 3 presents LSM and SE of bone breakings strengths and keel bone status of the two different laying lines and error probabilities between housing systems. 
Table 3

Least square means (LSM) and their standard errors (SE) for bone breaking strength and keel bone status by different laying lines and housing systems and their error probabilities (P) between factor levels (Least Square Mittelwerte (LSM) und deren Standardfehler für die Knochenbruchfestigkeiten und den Beinstatus nach Legelinien und Haltungssystemen und deren Irrtumswahrscheinlichkeiten (P) zwischen den Faktorstufen)

\begin{tabular}{llllllllll}
\hline Trait & FC (I) & \multicolumn{3}{c}{ SG (II) } & \multicolumn{2}{c}{ Aviary (III) } & P & \\
& LSM & SE & LSM & SE & LSM & SE & I-II & I-III & II-III \\
\hline Humerus LS (N) & 159.5 & 6.6 & 185.6 & 6.7 & 293.8 & 12.7 & $* *$ & $* * *$ & $* * *$ \\
Humerus LT (N) & 182.3 & 6.5 & 185.7 & 6.7 & 281.3 & 12.7 & n.s. & $* * *$ & $* * *$ \\
Tibia LS (N) & 109.1 & 2.8 & 120.0 & 2.8 & 156.3 & 4.8 & $* *$ & $* * *$ & $* * *$ \\
Tibia LT (N) & 122.4 & 2.7 & 123.8 & 2.8 & 156.6 & 4.9 & n.s. & $* * *$ & $* * *$ \\
Keel bone LS (1-4) & 3.5 & 0.1 & 3.4 & 0.1 & 3.4 & 0.1 & n.s. & n.s. & n.s. \\
Keel bone LT (1-4) & 3.6 & 0.1 & 3.7 & 0.1 & 3.5 & 0.1 & n.s. & n.s. & n.s. \\
\hline
\end{tabular}

FC: furnished cage system Aviplus; SG: small group system Eurovent 625a-EU; LS: Lohmann Silver; LT: Lohmann Tradition; n.s.: not significant, $\mathrm{P}>0.05 ; * *$ : $\mathrm{P} \leq 0.01$; ***: $\mathrm{P} \leq 0.001$.

Humerus and tibia breaking strengths of LS layers were significantly higher in SG compared to the FC. However, bone strengths of hens housed in the aviary system were significantly higher to both the SG and FC system. No differences in humerus and tibia bone breaking strengths could be detected for LB layers housed in the SG and FC, whereas differences between the aviary and the other two systems were significant. Keel bone status within laying line did not differ significantly between the three housing systems tested. Table 4 presents LSM and SE of keel bone status of the different laying months tested.

Table 4

Least square means (LSM) and their standard errors (SE) for keel bone status of each housing system and laying month and error probabilities (P) among laying months within each housing system (Least Square Mittelwerte (LSM) und deren Standardfehler für den Beinstatus nach Haltungssystemen und Legemonat und deren Irrtumswahrscheinlichkeiten (P) zwischen Legemonaten innerhalb Haltungssystem)

\begin{tabular}{|c|c|c|c|c|c|c|c|c|c|c|}
\hline \multirow{2}{*}{$\begin{array}{l}\text { Keel bone } \\
\text { status (1-4) }\end{array}$} & \multicolumn{4}{|c|}{ Laying month } & \multicolumn{6}{|l|}{$\mathrm{P}$} \\
\hline & 3 & 6 & 9 & 11 & $3-6$ & $3-9$ & 3-11 & $6-9$ & $6-11$ & 9-11 \\
\hline FC & $3.8 \pm 0.1$ & $3.8 \pm 0.1$ & $3.1 \pm 0.1$ & $3.4 \pm 0.1$ & n.s. & $* * *$ & n.s. & $* * *$ & $*$ & n.s. \\
\hline SG & $3.3 \pm 0.1$ & $3.8 \pm 0.1$ & $3.5 \pm 0.1$ & $3.4 \pm 0.1$ & $*$ & n.s. & n.s. & n.s. & $*$ & n.s. \\
\hline Aviary & $3.7 \pm 0.2$ & $3.7 \pm 0.2$ & $3.2 \pm 0.2$ & $3.2 \pm 0.2$ & n.s. & n.s. & $*$ & n.s. & $*$ & n.s. \\
\hline
\end{tabular}

FC: furnished cage system Aviplus; SG: small group system Eurovent 625a-EU; n.s.: not significant, P > 0.05; *: P $\leq 0.05$; ***: P $\leq$ 0.001; LS: Lohmann Silver; LT: Lohmann Tradition.

Results of keel bone status in the 11th laying month differed significantly from findings in the 6th laying month, thus reflecting an increase of deformities towards the end of the laying period in all housing systems tested. Least square means (LSM) and standard errors (SE) of the egg quality traits investigated for the different housing systems are presented in Table 5.

Table 5

Least square means (LSM) and their standard errors (SE) for egg quality traits and error probabilities (P) between housing systems (Least Square Mittelwerte (LSM) und deren Standardfehler für die Eiqualitätsmerkmale nach Haltungssystemen und deren Irrtumswahrscheinlichkeiten (P) zwischen den Haltungssystemen)

\begin{tabular}{llllllllll}
\hline Trait & FC & \multicolumn{3}{c}{ SG (II) } & \multicolumn{2}{c}{ Aviary (III) } & P & & II-III \\
& LSM & SE & LSM & SE & LSM & SE & I-II & I-III & $* *$ \\
\hline Shell strength $(\mathrm{N})$ & 40.7 & 0.3 & 39.6 & 0.2 & 40.6 & 0.3 & $* *$ & n.s. & $* *$ \\
Shell thickness $(\mu \mathrm{m})$ & 343.6 & 0.8 & 342.3 & 0.8 & 346.1 & 1.3 & n.s. & n.s. & $* *$ \\
Shell density $\left(\mathrm{mg} / \mathrm{cm}^{2}\right)$ & 87.9 & 0.2 & 86.6 & 0.2 & 87.7 & 0.3 & $* *$ & n.s. & $* *$ \\
Egg weight $(\mathrm{g})$ & 64.9 & 0.1 & 64.4 & 0.1 & 65.2 & 0.1 & $* *$ & n.s. & $* * *$ \\
\hline
\end{tabular}

FC: furnished cage system Aviplus; SG: small group system Eurovent 625a-EU; n.s.: not significant, P > 0.05; **: P $\leq 0.01$; $* * *: \mathrm{P} \leq 0.001$. 
Shell breaking strength, shell density, shell thickness and egg weight were significantly higher in the aviary system compared to SG. All egg quality traits presented except shell thickness turned out to be significantly higher in the FC in comparison to SG.

\section{Discussion}

Egg shell breaking strength can be regarded as a trait of major commercial importance. A high incidence of cracked eggs easily spoils financial gains. Literature findings on egg shell breaking strength are very diverse. Some authors described an increased shell breaking strength in aviary systems, whereas other studies did not detect differences of shell breaking strength between cage and alternative housing systems (VAN DEN BRAND et al., 2004). In the present investigation, the lowest shell breaking strength was found in the SG (39.6 N). Compared to a study by LEYENDECKER et al. (2005), shell breaking strengths of LS hens kept in an aviary (38.1 N) and furnished cage system (36.6 N) were exceeded by the present findings. In an investigation by VITS et al. (2005) egg quality of layers housed in two different small group systems was compared to furnished cages. The small group systems reflected a tendency to improve egg shell breaking strength. In the present study egg shell strength could not be increased by layers kept in the SG system, but compared to findings in earlier investigations, the shell breaking strength measured met a high egg quality standard. WHITEHEAD (2004) proposed that hens with a favourable predisposition of stronger bones provide less calcium for egg shell formation. This might be part of an explanation for the lower shell breaking strength of eggs found in SG compared to the other two systems. Bone strength of hens in SG was stimulated in comparison to FC. Hence, calcium might be preferentially used for bone remodelling and conservation rather than for egg shell composition.

With reference to health and welfare issues, osteoporosis of layers is one of the major concerns related to conventional cages. In a variety of studies on furnished cages, the incorporation of perches served to improve bone strength of layers (ABRAHAMSSON et al., 1993). Small group housing systems are designed to ameliorate bone strength by the provision of perches together with a larger floor space. VITS et al. (2005) compared bone strengths of layers kept in a small group housing system and furnished cages. Humerus strength was found to be higher in the furnished cage system, whereas tibia strength did not differ significantly between the systems. Bone strengths were clearly increased compared to conventional cages. In the current investigation, humerus and tibia strengths of LS hens kept in SG significantly exceeded bone strengths measured in FC. Humerus and tibia strengths of LT kept in SG showed a tendency to improved bone strengths compared to FC. Nevertheless, bone strengths measured in the aviary system were not reached. Humerus bone strength of hens housed in SG clearly exceeded bone strength reported by LEYENDECKER et al. (2005) for LS layers kept in furnished cages (129.6N). Tibiae strengths between these two investigations hardly differed. This result corresponds to other findings in the literature. The impact of a housing system on tibia bone strength has often been reported to be less distinct compared to humerus bone strength (VITS et al., 2005; HUGHES et al., 1993). In a study by BISHOP et al. (2000) the inheritance of bone strength characteristics was revealed. Sole selection on improved bone strength would 
have inevitably resulted in increased body weight. In the present study hens in the aviary system had the strongest bones and showed the lowest mean body weight (1994g) compared to hens kept in SG (2067g) and FC (2073g). The provision of more space together with the incorporation of perches in the aviary and small group housing system enabled hens to perform more movements. As a result, bone strength was stimulated and body weight was reduced within physiological limits.

The type of housing system does not only influence bone strength but also affects the status of keel bone. Due to its exposed anatomical location, keel bone is very vulnerable to deformations. Accidental collisions with the equippment, extended perching and the resulting compression are likely to impact keel bone condition. Deformities seem to be strongly associated with the incorporation of perches. APPLEBY et al. (1993) described a significantly higher incidence of keel bone deformations of hens kept in furnished cages compared to conventional cages. WEITZENBÜRGER et al. (2006) could show significant differences in keel bone status between the small group system Eurovent 625a-EU (Group size: 40 or 60 hens) and Eurovent 625A-EU (Group size: 10 or 20 hens) as well as furnished cages. The mean score for keel bone status was $3.5 \pm 0.05$ for the furnished cages and Eurovent 625A-EU, whereas in Eurovent 625a-EU the score improved to $3.7 \pm 0.05$. In addition, there was a positive significant correlation between a higher score for keel bone status (less deformities) and tibia and humerus bone strength in Lohmann Selected Leghorn and Lohmann Brown layers (WEITZENBÜRGER et al., 2006). FREIRE et al. (2003) detected old keel fractures in $73 \%$ of birds kept in aviary systems. Thus, hens in aviary systems and furnished cages are mostly predisposed to produce keel bone alterations. Keel bone deformities become manifest in the form of twists, osteal proliferations and dorso-ventral compressions. FLEMING et al. (2004) detected fracture callus material in all cases of deformities. In the present study, keel bone status of hens in the aviary system tended to be lower scored compared to SG and FC at the end of the laying period. In SG, the lowest-rated keel bone conditions were recorded in the 3rd and 11th laying month. Keel bone might not have been fully ossified in the 3rd laying month and therefore being very vulnerable to external influences. Also, it might have been taken a longer time for hens to establish a social ranking within a group size of 40 or 60 hens compared to the smaller group sizes of FC. This might have led to more agitation, thus causing collision with perches. A study by KEELING et al. (2003) indicated that intermediate group sizes between 30 and 60 hens suffer from a high degree of social disruption. In all housing systems tested, in agreement with WEITZENBÜRGER et al. (2006), keel bone status significantly deteriorated from the 9th to the 11th laying month. In contrast to WEITZENBÜRGER et al. (2006), no statistically significant differences of keel bone status could be found between the three housing systems at the end of the laying period. The reason for the missing significant differences among housing systems in the present study were the small differences in the keel bone status of Lohmann Silver Layers among housing systems and standard errors for Lohmann Tradition laying hens as two times as large compared to the study of WEITZENBÜRGER et al. (2006).

The current study showed that the development of small group housing systems seems to be a well suitable option to alternative housing systems. In SG, internal and external egg quality met a high qualitative standard together with the other two systems tested. For a more comprehensive evaluation of economic parameters, the amount of dirty and 
cracked eggs should be analysed together with data on egg production. With reference to bone strength, results on improved bone breaking strengths of hens housed in SG compared to layers in FC are very promising. The provision of more space due to larger group sizes seems to affect bone strength in a very positive way. Further research would be suggested on cage equipment, particularly perches. As the incorporation of perches is closely linked with both increased bone strength and the incidence of keel bone deformities, research should be stimulated in order to optimise these two parameters.

\section{References}

ABRAHAMSSON, P.; TAUSON, R.:

Effect of perches at different positions in conventional cages for laying hens of two different strains. Acta Agric. Scand., Sect. A, Animal Sci. 43 (1993), 228-235

APPLEBY, M.C.; SMITH, S.F.; HUGHES, B.O.:

Nesting, dust bathing and perching by laying hens in cages: effects of design on behaviour and welfare. Br. Poult. Sci. 34 (1993), 835-847

BISHOP, S.C.; FLEMING, R.H.; MCCORMACK, H.A.; FLOCK, D.K.: WHITEHEAD, C.C.:

The inheritance of bone characteristics affecting osteoporosis in laying hens. Poult. Sci. 41 (2000), 33-40

FLEMING, R.H.; MCCORMACK, L.; MCTEIR, L.; WHITEHEAD, C.C.:

Incidence, pathology and prevention of keel bone deformities in the laying hen. Br. Poult. Sci. 45 (2004), 320-330

FREIRE, R.; WILKINS, L.J.; SHORT, F.; NICOL, C.J.:

Behaviour and welfare of individual laying hens in a non-cage system. Br. Poult. Sci. 44 (2003), 22-29

HUGHES B.O.; WILSON, W.; SMITH, S.F.:

Comparison of bone volume and strength as measures of skeletal integrity in caged laying hens with access to perches. Res. Vet. Sci. 54 (1993), 202-206

KEELING, L.J.; ESTEVEZ, I.; NEWBERRY, R.C.; CORREIA, M.G.:

Production-related traits of layers reared in different sized flocks: the concept of problematic intermediate group sizes. Poult. Sci. 82 (2003), 1393-1396

LEYENDECKER, M.; HAMANN, H.; HARTUNG, J.; KAMPHUES J.; NEUMANN, U.; SÜRIE, C.; DISTL, O.:

Keeping laying hens in furnished cages and an aviary housing system enhances their bone stability. Br. Poult. Sci. 46 (2005), 536-544

VAN DEN BRAND, H.; PARMENTIER, H.K.; KEMP, B.:

Effects of housing system (outdoor vs cages) and age of laying hens on egg characteristics. Br. Poult. Sci. 45 (2004), 745-752

VITS, A.; WEITZENBÜRGER, D.; HAMANN, H.; DISTL, O.:

Production, egg quality, bone strength, claw length, and keel bone deformities of laying hens housed in furnished cages with different group sizes. Poult. Sci. 84 (2005), 1511-1519

WEITZENBUERGER, D.; VITS, A.; HAMANN, H.; DISTL, O.: Evaluation of small group housing systems and furnished cages concerning keel bone deformities, plumage condition, claw length and body weight in layer lines Lohmann Selected Leghorn and Lohmann Brown. Arch. Tierz., Dummerstorf 46 (2006), 89-102

WHITEHEAD, C.C.:

Overview of bone biology in the egg-laying hen. Poult. Sci. 83 (2004), 193-199

Corresponding author:

Prof. Dr. OTTMAR DISTL

Institute for Animal Breeding and Genetics

University of Veterinary Medicine Hannover

Bünteweg 17p

30559 Hannover, Germany

email: ottmar.distl@tiho-hannover.de 